\title{
Salinomycin inhibits the growth of colorectal carcinoma by targeting tumor stem cells
}

\author{
CHEN ZHANG $^{1}$, YAPING TIAN ${ }^{3}$, FEIYU SONG ${ }^{2}$, CHANGHAO FU $^{1}$, BO HAN $^{1}$ and YI WANG $^{1}$ \\ ${ }^{1}$ Department of Regenerative Medicine, School of Pharmaceutical Sciences, Jilin University, Changchun, Jilin 130021; \\ ${ }^{2}$ Jilin Connell Pharmaceutical Company, Changchun, Jilin 130000; ${ }^{3}$ Department of Dermatology, \\ First Hospital of Jilin University, Changchun, Jilin 130021, P.R. China
}

Received June 12, 2015; Accepted July 23, 2015

DOI: $10.3892 /$ or.2015.4253

\begin{abstract}
Salinomycin is a monocarboxylic polyether antibiotic that has been reported to induce apoptosis in various types of cancer cells with specificity for cancer stem cells. However, its anticancer effect in colorectal cancer stem cells has never been reported. In the present study, we examined the ability of salinomycin to induce cell death in the colorectal cancer stem cell line CD $44^{+} \mathrm{EpCAM}^{+}$HCT-116, and we measured its in vivo tumor inhibition capacity. Salinomycin dose-dependently induced cytotoxicity in the $\mathrm{CD}_{4}{ }^{+} \mathrm{EpCAM}^{+} \mathrm{HCT}-116$ cells and inhibited colony formation. Salinomycin treatment was shown to induce apoptosis, as evidenced by nuclear fragmentation, an increase in the proportion of acridine orange/ethidium bromide-positive cells and an increase in the percentage of Annexin V-positive cells. Apoptosis was induced in colorectal cancer stem cells in a caspase-dependent manner, as shown by an increase in the levels of cleaved caspase-3, -8 and -9 . JC-1 staining further revealed that salinomycin induced colorectal cancer cell apoptosis via the mitochondrial pathway. In addition, salinomycin treatment of xenograft mice inhibited the growth of tumors derived from the CD $44^{+} \mathrm{EpCAM}^{+}$HCT-116 cells. The present study demonstrated that the antibiotic salinomycin exerts an anti-colorectal cancer effect in vitro and in vivo, suggesting salinomycin as a potential drug for colorectal cancer therapy.
\end{abstract}

\section{Introduction}

Colorectal cancer (CRC) is the third most common malignancy worldwide, accounting for $\sim 10 \%$ of all cancer cases and CRC is one of the most common causes of death related to gastrointestinal cancers (1-3). Although the incidence rates of colon cancer have declined somewhat, current therapies are associated with serious side-effects, high

Correspondence to: Professor Yi Wang, Department of Regenerative Medicine, School of Pharmaceutical Sciences, Jilin University, 1266 Fujin Road, Changchun, Jilin 130021, P.R. China

E-mail:wangyi@jlu.edu.cn

Key words: colorectal cancer stem cells, salinomycin, apoptosis, caspase family, Bcl-2 family cost and recurrence rates exceeding $50 \%$, primarily due to the development of acquired chemoresistance to conventional chemotherapeutics $(4,5)$.

Emerging data suggest that malignant tumors contain a small distinct population of cancer stem cells (CSCs), which are responsible for tumor initiation and propagation (6). Stem cell research and the cancer stem cell (CSC) hypothesis have shown that colonic stem cells or CSCs are involved in tissue regeneration and colonic carcinogenesis (7-9). Drug-resistant CSCs are thought to be one of the key causes of CRC treatment failure, and it is hypothesized that these cells are ultimately the likely cause of metastasis and tumor recurrence (10-12). Most modern treatments are ineffective against solid tumors and this may be the result of the increased resistance of CSCs (13). Therefore, it is vital to find novel therapeutic methods to eradicate CSCs and enable the development of more effective treatment protocols (14).

Salinomycin is a 751-Da monocarboxylic polyether antibiotic, which was initially used to eliminate bacteria, fungi and parasites and is fed to ruminants to improve nutrient absorption and feeding efficiency $(15,16)$. This compound is now considered an important anticancer drug candidate $(17,18)$. It has recently been reported that salinomycin can selectively kill human breast cancer stem cells, and is 100 -fold more effective at reducing the proportion of CSCs than paclitaxel, albeit by an unknown mechanism (19). Salinomycin was also found to be a selective inhibitor of human lung, gastric, osteosarcoma, squamous cell carcinoma, prostate and pancreatic CSCs (20-25). However, since the mechanism involved in the salinomycin anti-CSC activity is poorly understood, it is necessary to conduct more in-depth research into the activity of salinomycin in different types of human CSCs. In the present study, we found that salinomycin selectively induced apoptosis in human colorectal cancer stem cells (CRSCs) by activating a distinct apoptotic pathway. The apoptosis was accompanied by caspase activation, increased DNA damage, loss of membrane potential and regulation of the $\mathrm{Bcl}-2 / \mathrm{Bax}$ ratio. Our results indicate that salinomycin may be a novel therapy for CRC.

\section{Materials and methods}

Cell lines and culture. HCT-116 human CRC cells were purchased from the Cell Bank of the Chinese Academy of 
Sciences (Shanghai, China), and maintained in McCoy's 5A (Sigma-Aldrich, St. Louis, MO, USA). Media contained $100 \mathrm{IU}$ penicillin, $100 \mu \mathrm{g} / \mathrm{ml}$ streptomycin (Invitrogen, Carlsbad, CA, USA) and $10 \%$ fetal bovine serum (FBS; Gibco-BRL, Grand Island, NY, USA). The cells were incubated at $37^{\circ} \mathrm{C}$ in $5 \% \mathrm{CO}_{2}$. CD44 ${ }^{+} \mathrm{EpCAM}^{+} \mathrm{HCT}-116$ cells (CRSCs) were maintained in Dulbecco's modified Eagle's medium (DMEM)/F12 (Sigma-Aldrich) containing 2\% B27 (Invitrogen), $20 \mathrm{ng} / \mathrm{ml}$ epidermal growth factor, and $20 \mathrm{ng} / \mathrm{ml}$ basic fibroblast growth factor (both from PeproTech, Rocky Hill, NJ, USA) in an incubator at $37^{\circ} \mathrm{C}$ in $5 \% \mathrm{CO}_{2}$.

Drugs and antibodies. Salinomycin (Sigma-Aldrich) was stored as a $500 \mathrm{mM}$ dimethylsulfoxide (DMSO; Gibco, CA, USA) solution in the dark at $-20^{\circ} \mathrm{C}$. For experiments, salinomycin solutions were prepared by diluting the stock solution with DMEM/F12. The antibodies used for western blotting were as follows: rabbit anti-caspase-3 and anti-caspase-6, mouse anti-Bcl-2, anti-Bax, anti-caspase- 8 anti-caspase- 9 and anti- $\beta$-actin. All antibodies were purchased from Santa Cruz Biotechnology (Santa Cruz, CA, USA). CD44 and epithelial cell adhesion molecule (EpCAM) antibodies (eBioscience, San Diego, CA, USA) were used for magnetic-activated cell sorting (MACS).

MACS. MACS was performed using a CELLection ${ }^{\mathrm{TM}}$ Biotin Binder kit according to the manufacturer's instructions (Invitrogen). In brief, HCT-116 cells were collected and incubated with the CD44 antibody for $10 \mathrm{~min}$. Dynabeads (750 $\mu \mathrm{l})$ were added to the cells, which were then incubated for $20 \mathrm{~min}$ and separated using a magnet. Subsequently, releasing buffer (DNase I; $120 \mu \mathrm{l}$ ) was added, and the cells were incubated for $15 \mathrm{~min}$ at room temperature with gentle tilting and rotation to collect target cells (CD44 ${ }^{+}$cells). $\mathrm{CD} 44^{+}$cells were incubated with the EpCAM antibody for $10 \mathrm{~min}$, and Dynabeads $(25 \mu \mathrm{l})$ were added to the cells. The cells were incubated for $20 \mathrm{~min}$ and then separated using a magnet. Subsequently, releasing buffer (DNase I; $4 \mu \mathrm{l}$ ) was added and the cells were incubated for $15 \mathrm{~min}$ at room temperature with gentle tilting and rotation to collect target cells $\left(\mathrm{EPCAM}^{+} \mathrm{CD} 44^{+}\right.$cells, CRSCs).

Serum-induced differentiation. To induce differentiation, CRSCs were collected and maintained in DMEM/F12 medium supplemented with $10 \%$ FBS and incubated for 3 days. Results were analyzed using an inverted microscope.

Soft agar colony formation. One hundred living cells mixed with $0.3 \%$ agar liquor were immediately plated onto a $0.5 \%$ solidified agar-based 6-well plate. Cells were incubated for 3 weeks on soft agar culture medium. The resulting colonies were photographed with an optical microscope.

Cell viability. HCT-116 cells and CRSCs were plated at a density of 5,000 cells/well in flat-bottom 96 -well plates (100 $\mu \mathrm{l}$ medium/well). After $24 \mathrm{~h}$, the cells were treated with salinomycin at various concentrations (1,10 and $25 \mu \mathrm{M})$, $100 \mu \mathrm{M}$ cisplatin (DDP) as a positive parallel control or $0.1 \%$ DMSO as a solvent control. After $48 \mathrm{~h}$, the Cell Counting Kit-8 (CCK-8; Dojindo, Tokyo, Japan) was used according to the manufacturer's instructions, optical density was measured using a microplate reader at $450 \mathrm{~nm}$, and the cell viability was calculated. All experimental concentrations were assessed in triplicate. Inhibition ratio was calculated using the formula: Inhibition ratio $(\%)=1-\mathrm{OD}_{\text {treatment group }} / \mathrm{OD}_{\text {solvent control }} \mathrm{x} 100$.

Invasion assay. An invasion assay was performed using 6.5-mm Transwell ${ }^{\circledR}$ plates with sterile $8.0-\mu \mathrm{m}$ pore polycarbonate membrane inserts (Corning, Steuben County, NY, USA). In brief, 5,000 CRSCs in DMEM/F12 medium were seeded in the insert and treated with salinomycin $(0-25 \mu \mathrm{M})$. The lower chamber was filled with DMEM/F12 medium supplemented with $10 \% \mathrm{FBS}$ as a chemotactic factor, and the plates were subsequently incubated at $37^{\circ} \mathrm{C}$ in $5 \% \mathrm{CO}_{2}$ for $48 \mathrm{~h}$. The insert chamber contained an $8-\mu \mathrm{m}$ pore polycarbonate membrane covered with a thin layer of BD Matrigel ${ }^{\mathrm{TM}}$ (BD, San Diego, CA, USA). The Matrigel layer blocks pores in the membrane, which prevents the migration of non-invasive cells; however, invading cells can migrate through the Matrigel layer and eventually attach themselves to the bottom of the polycarbonate layer. After $48 \mathrm{~h}$, the number of cells in the lower chamber was quantified using the CCK- 8 assay as described above.

DNA ladder assay. Apoptotic response was evaluated by detecting DNA fragmentation using an apoptosis DNA ladder detection kit (KeyGen, Nanjing, China). CRSCs were treated with salinomycin $(1,10$ or $25 \mu \mathrm{M}), 100 \mu \mathrm{M}$ DDP as a positive parallel control, or $0.1 \%$ DMSO as solvent control. After $48 \mathrm{~h}$, CRSCs were collected and washed with PBS, resuspended in $20 \mu 1$ lysis buffer, and lysed for $10 \mathrm{~min}$ on ice. Subsequently, enzyme A $(10 \mu \mathrm{l})$ was added and incubated at $37^{\circ} \mathrm{C}$ for $1 \mathrm{~h}$. Then samples were incubated with enzyme B $(10 \mu \mathrm{l})$ at $50^{\circ} \mathrm{C}$ for $90 \mathrm{~min}$. After $2 \%$ agarose gel electrophoresis, DNA was stained with ethidium bromide (EB) and photographed.

Acridine orange $(A O)$ and $E B$ assay. $\mathrm{AO}$ is used to stain normal cells and EB indicates apoptotic cells. In brief, CRSCs were plated into 6-well plates and treated with salinomycin $(1,10$ and $25 \mu \mathrm{M}), 100 \mu \mathrm{M}$ DDP as a positive parallel control and $0.1 \%$ DMSO as a solvent control. After $48 \mathrm{~h}$, each well was treated with AO $(5 \mu 1)$ and EB (5 $\mu 1)$, and subsequently incubated for $5 \mathrm{~min}$ at room temperature. The stained cells were analyzed using a fluorescence microscope (Olympus, Tokyo, Japan). The experiments were repeated 3 times.

Annexin $V$ analysis. Annexin $\mathrm{V}$ analysis was performed using an Annexin V-fluorescein isothiocyanate (FITC) kit (BD Biosciences, Franklin Lakes, NJ, USA) according to the manufacturer's instructions. Briefly, after CRSCs were incubated with 1,10 or $25 \mu \mathrm{M}$ salinomycin, $100 \mu \mathrm{M}$ DDP as a positive parallel control or $0.1 \%$ DMSO as a solvent control, they were harvested by quick trypsinization to minimize potentially high Annexin $\mathrm{V}$ background levels in adherent cells. Cells were then washed twice with cold phosphate-buffered saline (PBS) and re-suspended in binding buffer at a concentration of $1 \times 10^{6}$ cells $/ \mathrm{ml}$. Cells $(100 \mu \mathrm{l})$ were stained with Annexin V-FITC (5 $\mu \mathrm{l})$ and propidium iodide (PI; $5 \mu \mathrm{l}$ ) and incubated in the dark at room temperature for $15 \mathrm{~min}$. Then, binding buffer $(400 \mu \mathrm{l})$ was added, and the cells were analyzed using a flow cytometer (Beckman 
Coulter, Salt Lake, UT, USA) and a fluorescence microscope (Olympus). Cells negative for both Annexin V and PI were viable, Annexin $\mathrm{V}^{+} / \mathrm{PI}^{-}$cells were in early apoptosis and Annexin $\mathrm{V}^{+} / \mathrm{PI}^{+}$cells were necrotic or in late apoptosis. The experiments were repeated 3 times.

JC-1 assay. JC-1 and FITC staining were carried out using a commercial mitochondrial membrane potential detection (JC-1) kit (BD Biosciences). Briefly, CRSCs were incubated with salinomycin $(1,10$ or $25 \mu \mathrm{M}), 100 \mu \mathrm{M}$ DDP as a positive parallel control or $0.1 \%$ DMSO as a solvent control for 48 h. CRSCs were harvested, then washed twice with cold PBS and re-suspended in binding buffer at a concentration of $1 \times 10^{6}$ cells $/ \mathrm{ml}$. Cells $(100 \mu \mathrm{l})$ were stained with JC-1 $(5 \mu \mathrm{l})$ and PI $(5 \mu \mathrm{l})$ and incubated in the dark at room temperature for $15 \mathrm{~min}$. Then, binding buffer $(400 \mu \mathrm{l})$ was added and cells were analyzed using a flow cytometer (Beckman Coulter). Cells negative for both JC-1 and PI were viable, $\mathrm{JC}-1^{+} / \mathrm{PI}^{+}$cells were in early apoptosis and $\mathrm{JC}-1^{+} / \mathrm{PI}^{-}$cells were necrotic or in late apoptosis. The experiments were repeated 3 times.

Quantitative real-time reverse transcriptase-polymerase chain reaction $(R T-q P C R)$. Total RNA was extracted using TRIzol reagent (Invitrogen). First-strand cDNA was reverse transcribed using PrimeScript RT kit (Takara, Otsu, Shiga, Japan) according to the manufacturer's protocol. Relative mRNA levels were quantitatively determined using a real-time PCR system. The primer sequences used for quantitative realtime PCR are shown in Table I. Glyceraldehyde-3-phosphate dehydrogenase (GAPDH) was used as the endogenous reference. cDNA was subjected to PCR for 40 cycles of $94^{\circ} \mathrm{C}$ for $30 \mathrm{sec}, 60^{\circ} \mathrm{C}$ for $30 \mathrm{sec}$ and $72^{\circ} \mathrm{C}$ for $45 \mathrm{sec}$. qPCR was performed using a Thermo ${ }^{\circledR}$ PikoReal 96 system (Thermo, Waltham, MA, USA). Real-time RT-qPCR was performed using FastStart Universal SYBR-Green Master (ROX) (Roche, Basle, Switzerland) and analyzed using PikoReal software 2.1 (Thermo). Experiments were performed in triplicate and the average $\mathrm{CT}$ values of target genes were normalized to control as $\Delta \mathrm{CT}$. Changes in expression levels are shown either as a fold increase or as a ratio (target gene/control gene).

Western blotting. Western blotting was carried out to test for caspase-3, -6, -8 and -9, Bcl-2 and Bax. To collect whole protein, cells were lysed with RIPA buffer containing protease inhibitor cocktail (Roche), and protein concentrations were determined using a BCA assay kit (Beyotime, Nanjing, Jiangsu, China). Protein bands were separated by $12 \%$ sodium dodecyl sulfate polyacrylamide gel electrophoresis (SDS-PAGE) and were then transferred to membranes (Millipore, Bedford, MA, USA) at $100 \mathrm{~V}$ for $45 \mathrm{~min}$ at room temperature. After blocking in $4 \%$ non-fat dry milk in tris-buffered saline (TBS), the membranes were incubated with primary antibodies at a 1:1,000 dilution in TBS overnight at $4^{\circ} \mathrm{C}$, washed 3 times with TBS containing $0.5 \%$ Tween-20, and then incubated with secondary antibodies conjugated with horseradish peroxidase (HRP) at a 1:5,000 dilution in TBS for $1 \mathrm{~h}$ at room temperature. Membranes were washed again in TBS containing $0.5 \%$ Tween-20 for 3 times at room temperature. Protein bands were visualized on X-ray film using enhanced chemiluminescence (ECL; GE Healthcare, Bethesda, MD, USA).
Table I. Real-time PCR primer sequences.

\begin{tabular}{lll}
\hline Gene & & \multicolumn{2}{c}{ Primer sequence $\left(5^{\prime} \rightarrow 3^{\prime}\right)$} \\
\hline Bcl-2 & F & CATGTGTGTGGAGAGCGTCAA \\
& R & GCCGGTTCAGGTACTCAGTCA \\
Bax & F & GATCCAGGATCGAGCAGA \\
& R & AAGTAGAAGAGGGCAACCAC \\
Caspase-3 & F & CAGAACTGGACTGTGGCATTGAG \\
& R & GGATGAACCAGGAGCCATCCT \\
Caspase-6 & F & AGAAAGATAGCAGCAGTGCCTCA \\
& R & ATTGCCAGTAGAAGTCTTCATGGTT \\
Caspase-8 & F & CAAGTTCCTGAGCCTGGACTACATT \\
& R & GACAGATTGCTTTCCTCCAACATT \\
Caspase-9 & F & GCGAACTAACAGGCAAGCAGC \\
& R & CGACATCACCAAATCCTCCAGAAC \\
GAPDH & F & CATCAGCAATGCCTCCTGCAC \\
& R & TGAGTCCTTCCACGATACCAAAGTT
\end{tabular}

F, forward; R, reverse.

CRSC xenograft studies. Severe combined immunodeficiency (SCID) mice (CB17/Icr-Prkdc ${ }^{\text {scid } / I c r l c o C r l V r) ~ w e r e ~ b r e d ~ i n ~}$ specific-pathogen-free microisolator cages that were purchased from the Animal Institute of the Chinese Academy of Medical Science. All experiments were performed according to the regulations of the Animal Care Committee of Jilin University. To generate CRSC xenografts, $1 \times 10^{5}$ CRSCs were resuspended in PBS $(100 \mu \mathrm{l})$ and injected subcutaneously into the right flank of the mice. The weight and size of the tumors were measured every other day. When tumors reached a volume of $40-60 \mathrm{~mm}^{3}$, the mice were randomized into therapy and control groups. After that, the mice were treated with vehicle (DMSO), 5-fluorouracil (5-FU), salinomycin or a combination of salinomycin and 5-FU. 5-FU was administered once a week $(100 \mathrm{mg} / \mathrm{kg}) 3$ times, while salinomycin was injected every other day $(4 \mathrm{mg} / \mathrm{kg}) 5$ times. Both agents were injected intraperitoneally. The animal weight and tumor volumes were monitored every other day. Using Vernier calipers, tumor volume was calculated according to the formula $\mathrm{A} \times \mathrm{B} \times \mathrm{B} / 2$, where $\mathrm{A}$ is the length of the tumor and $\mathrm{B}$ is the width.

Statistical analysis. All analyses were performed using Origin8 (Origin8 Technologies Ltd., London, UK) and data are presented as means \pm standard deviation (SD). Values of $\mathrm{P}<0.05$ were considered to be statistically significant and were evaluated using the Student's t-test.

\section{Results}

Biological characterization of CRSCs. The proportion of CRSCs in HCT-116 cells was found to be $3 \%$, and the CRSCs formed spheres after culturing for 10 days in CRSC medium (Fig. 1A). The generation of spheres was observed over the next 3 weeks in soft agar using an inverted 

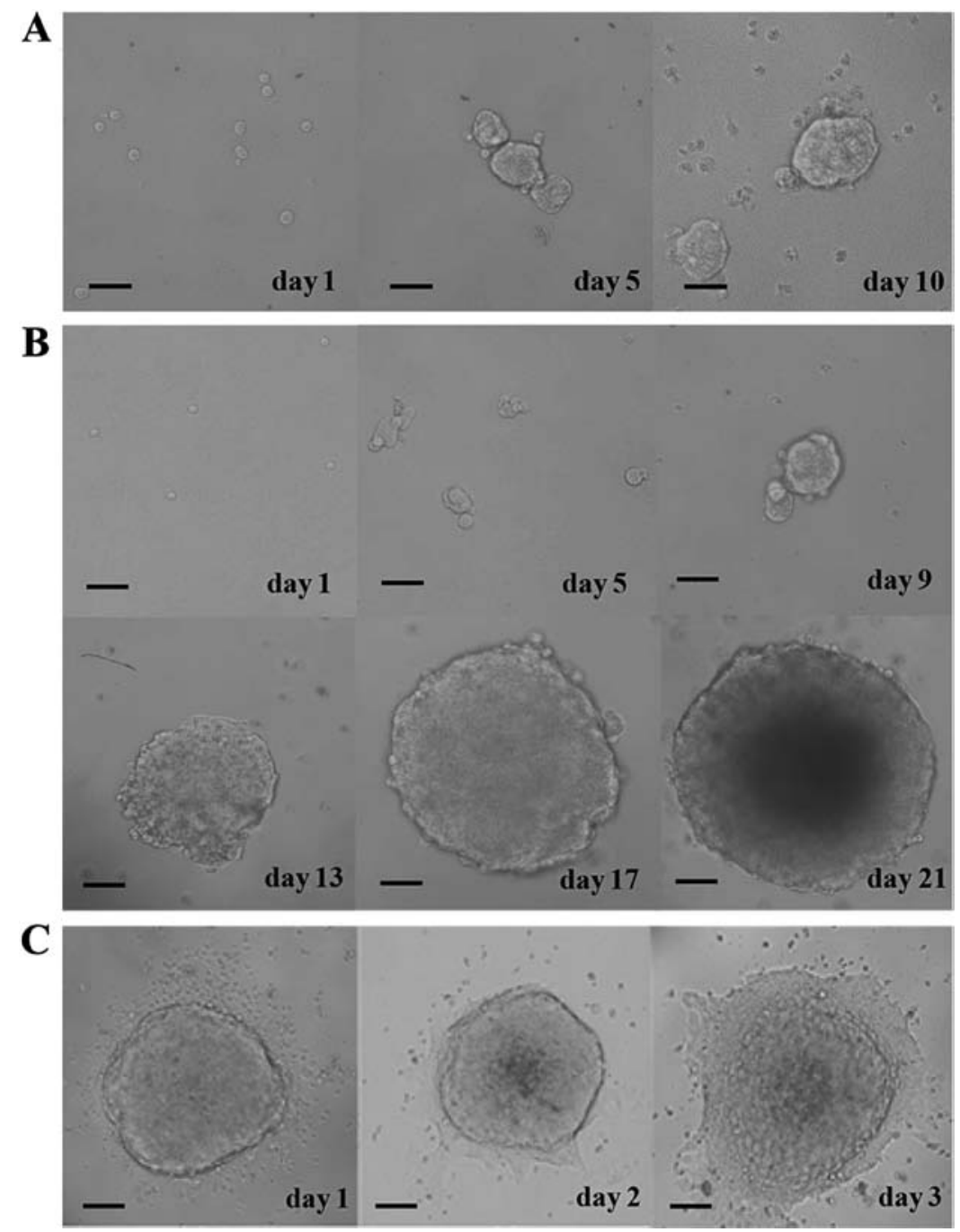

Figure 1. Optical micrographs of colorectal cancer stem cells (CRSCs). (A) Morphology of CRSCs over 10 days. (B) Formation of CRSC colonies over 21 days (C) Serum-induced differentiation of CRSCs into adherent cells. (Scale bar, $500 \mu \mathrm{m}$ ).

microscope (Fig. 1B). CRSC spheroid cells became adherent cells when serum was added to the culture medium (Fig. 1C).

Salinomycin inhibits the viability and invasion of CRSCs. To initially assess the anticancer effect of salinomycin on CRSCs, a CCK-8 assay was performed on the treated cells. Salinomycin reduced the cell viability of HCT-116 cells and CRSCs in a concentration-dependent manner (Fig. 2A). Additionally, the Transwell migration assay indicated that treatment with $25 \mu \mathrm{M}$ salinomycin significantly reduced the number of invasive cells (Fig. 2B).

Salinomycin induces the apoptosis of CRSCs. AO/EB staining indicated that the number of apoptotic CRSCs increased in response to salinomycin treatment in a concentration-dependent manner (Fig. 3A). The Annexin V/PI double staining assay revealed that salinomycin treatment increased the percentage of Annexin V-positive cells in the CRSCs (Fig. 3B and C). A DNA ladder assay indicated that severe nuclear fragmentation took place in the CRSCs following treatment with 10 or $25 \mu \mathrm{M}$ salinomycin, but not in the cells treated with DMSO or $1 \mu \mathrm{M}$ salinomycin (Fig. 3D).
Salinomycin-induced apoptosis of CRSCs is caspase-dependent. To further clarify the mechanism of salinomycin-induced apoptosis, the expression of a number of apoptosis-related proteins and their mRNAs were analyzed. Upregulation of caspase-3, -8 and -9 mRNA was observed in CRSCs treated with salinomycin for $48 \mathrm{~h}$ (Fig. 4A). Additionally, the protein expression of cleaved caspase-3, -8 and -9 was enhanced following treatment with salinomycin for $48 \mathrm{~h}$ (Fig. 4B).

Salinomycin induces cell apoptosis via the mitochondrial pathway. An increased level of cleaved caspase-9 implied the breakdown of mitochondria in the salinomycin-induced apoptosis. The JC-1 staining assay showed that the percentage of cells experiencing a loss of mitochondrial membrane potential increased from 17.29 to $78.81 \%$ in the CRSCs following treatment with $25 \mu \mathrm{M}$ salinomycin. The loss of mitochondrial membrane potential, along with increased cleaved caspase-9 (Fig. 4C and D), suggests that salinomycin-induced CRSCs death via the mitochondrial apoptosis pathway.

Salinomycin-induced apoptosis of CRSCs is dependent on the Bcl-2 family. We measured the expression of Bcl-2 and Bax 

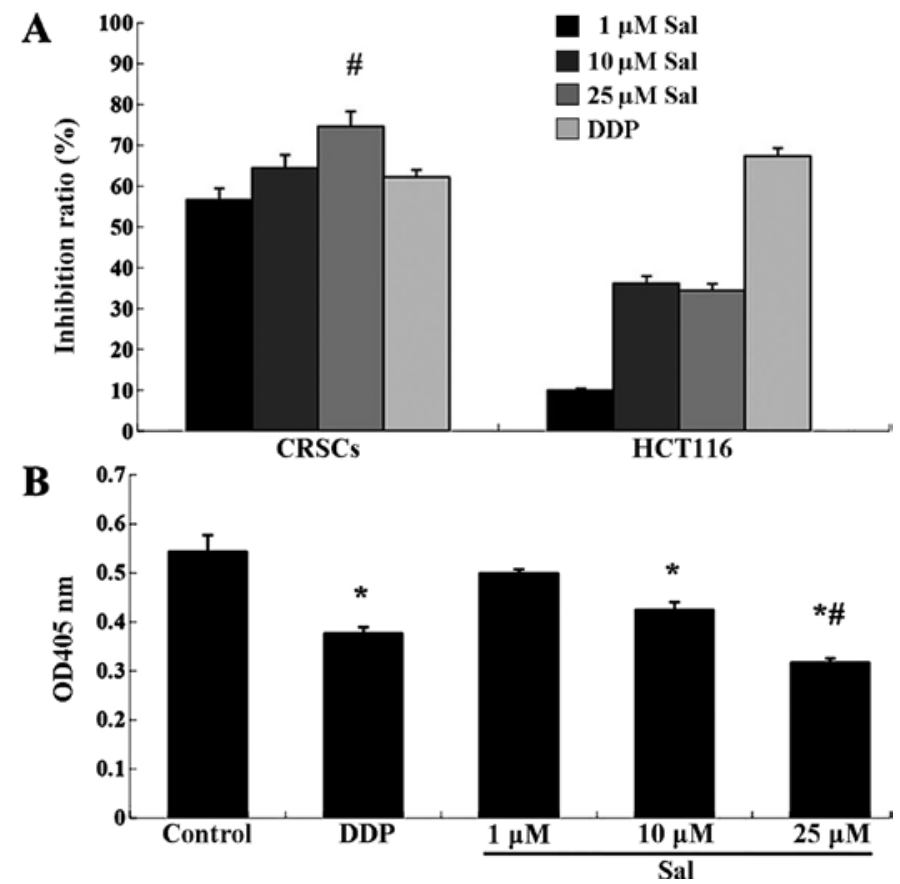

Figure 2. Salinomycin (Sal) inhibits cell proliferation and invasion of colorectal cancer stem cells (CRSCs). (A) Inhibition of the viability of CSRCs and HCT-116 cells with Sal or cisplatin (DDP) treatment. (B) Inhibition of CSRC invasiveness by Sal or DDP treatment (Control represents untreated CSRCs). Data represent the means $\pm \mathrm{SD}$ of triplicate measurements from one of three independent experiments. ${ }^{*} \mathrm{P}<0.05$, compared with the control; ${ }^{\sharp} \mathrm{P}<0.05$, compared with DDP.

A
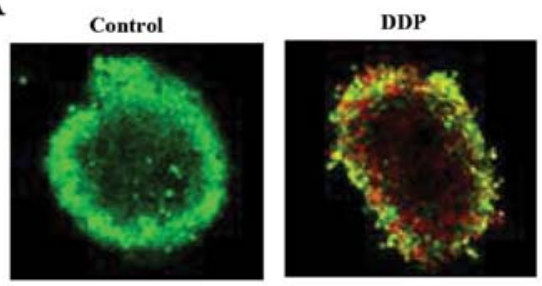

B

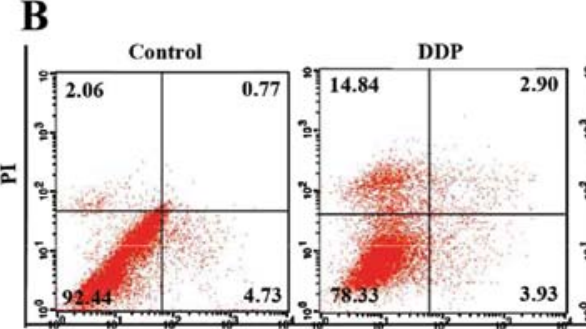

C

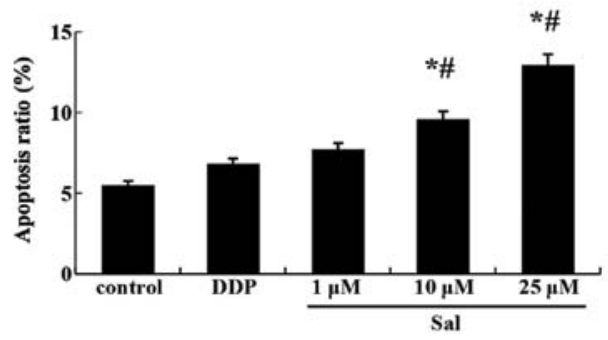

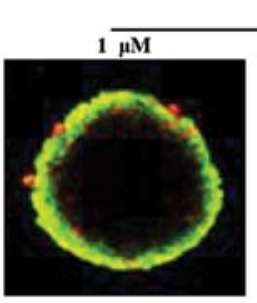
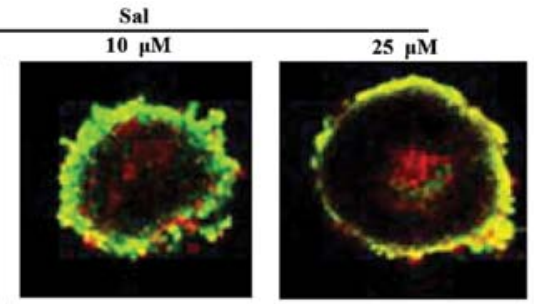

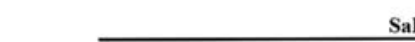
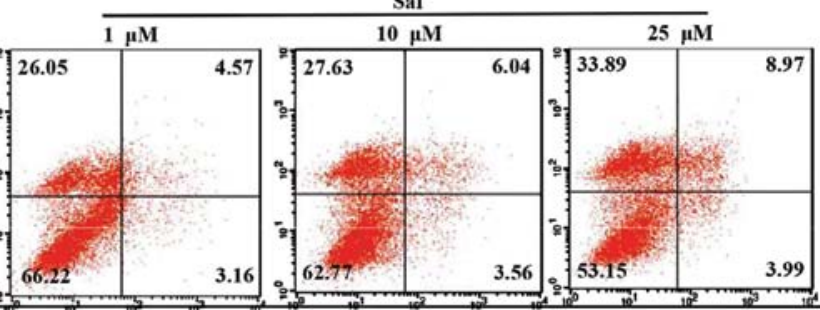

Annexin V/FITC


Figure 3. Salinomycin (Sal) induces apoptosis in colorectal cancer stem cells (CRSCs). (A) Fluorescence micrographs showing acridine orange/ethidium bromide staining of CRSCs following treatment with Sal. Normal cells are shown in green and apoptotic cells are shown in red. (B) Flow cytometric analyses of Annexin V/propidium iodide (PI) staining of CRSCs following Sal or DDP treatment. Dot plots show Annexin V-fluorescein isothiocyanate (FITC) and PI fluorescence staining. Lower-left quadrant, viable cells; lower-right and upper-right quadrants, apoptotic cells; upper-left quadrant, necrotic cells. (C) Percentage of CRSCs undergoing apoptosis following Sal or DDP treatment according to Annexin V assay. (D) Detection of apoptotic DNA following treatment of CSRCs with Sal or cisplatin (DDP). Data represent the means \pm SD of triplicates from one of three independent experiments. ${ }^{*}<<0.05$, compared with the control; ${ }^{~} \mathrm{P}<0.05$, compared with DDP. 

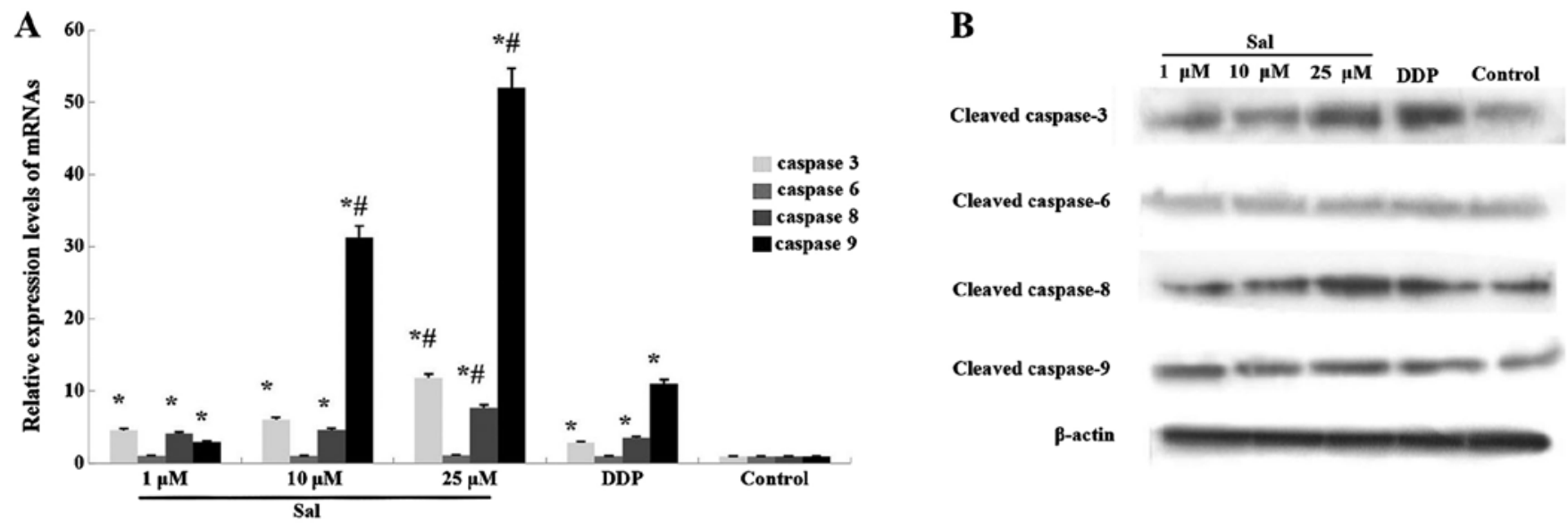

C

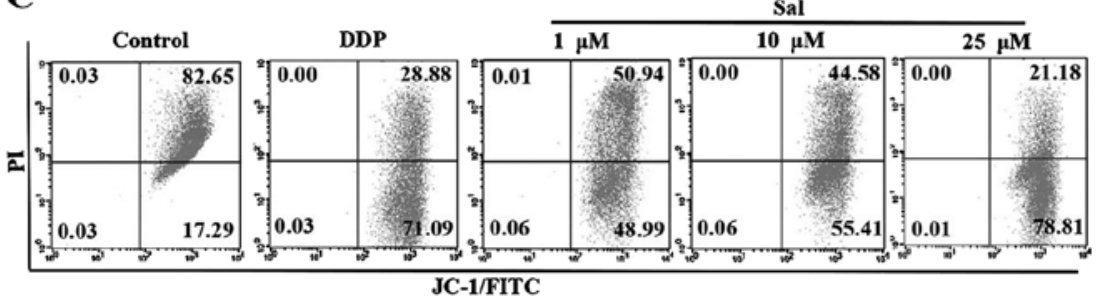

$\mathbf{D}$

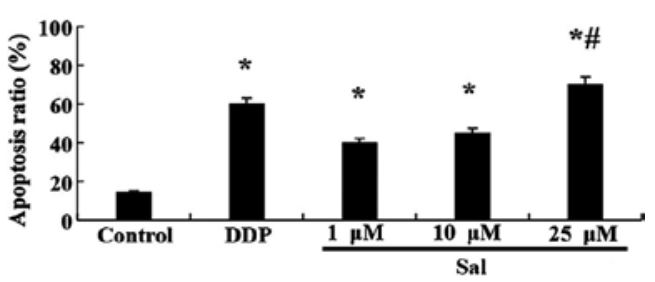

Figure 4. Salinomycin (Sal) induces apoptosis in colorectal cancer stem cells (CRSCs) via the caspase family and the mitochondrial pathway. (A) Quantitative real-time polymerase chain reaction analyses showing mRNA levels of cleaved caspase-3, $-6,-8$ and -9 following treatment of CSRCs with Sal or cisplatin (DDP). (B) Western blotting shows protein levels of cleaved caspase-3, -6, -8 and -9 following treatment of CSRCs with Sal or DDP. (C) JC-1 staining assay following treatment of CSRCs with Sal or DDP. Apoptotic cells are shown in the lower right quadrant of the dot plots. (D) Percentage of CRSCs undergoing apoptosis following Sal or DDP treatment according to JC-1 assay. Data represent the means \pm SD of triplicates from one of three independent experiments. ${ }^{*} \mathrm{P}<0.05$, compared with the control; ${ }^{\#} \mathrm{P}<0.05$, compared with DDP.
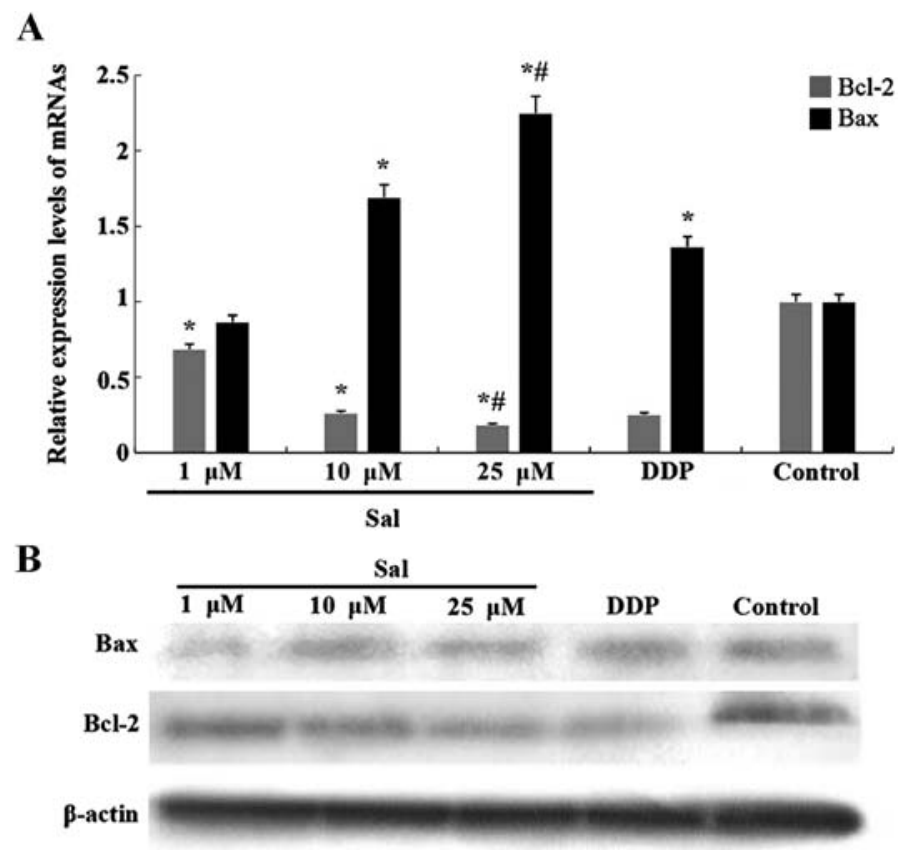

Figure 5. Salinomycin (Sal) regulates Bcl-2 in colorectal cancer stem cells (CRSCs). (A) Quantitative real-time polymerase chain reaction analyses showing mRNA levels of Bax and Bcl-2 following treatment of CSRCs with Sal or cisplatin (DDP). (B) Western blotting shows protein levels of Bax and Bcl-2 following treatment of CSRCs with Sal or DDP. Data represent the means \pm SD of triplicates from one of three independent experiments. "P $<0.05$, compared with the 2 control; " $\mathrm{P}<0.05$, compared with DDP.

using western blotting and real-time RT-qPCR. Salinomycin treatment for $48 \mathrm{~h}$ significantly suppressed the expression of Bcl-2 and upregulated the expression of Bax in the CRSCs (Fig. 5A and B).
Salinomycin inhibits tumor growth in vivo. To evaluate the in vivo anticancer activity of salinomycin, CRSCs were subcutaneously injected into SCID mice in the right flank. Delayed tumor growth was observed in the salinomycin-treated 

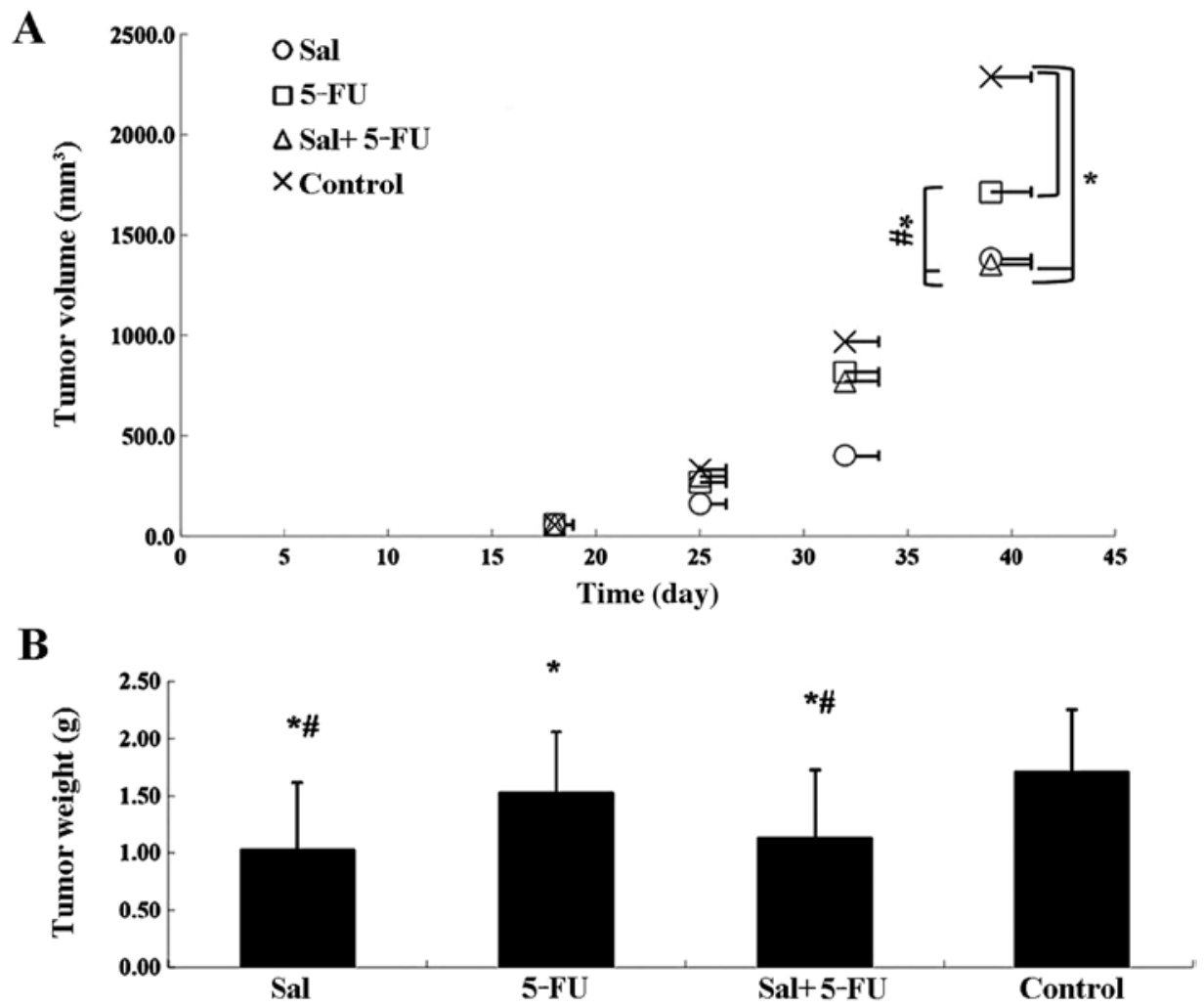

Figure 6. Salinomycin (Sal) inhibits the growth of tumors in cancer stem cell xenograft mice. (A) Growth over time and (B) the weight of tumors in the colorectal cancer stem cell xenograft mice following treatment with Sal, 5-fluorouracil (5-FU) or a combination of both. Data represent the means \pm SD. ${ }^{*} \mathrm{P}<0.05$, compared with the control; ${ }^{*} \mathrm{P}<0.05$, compared with DDP.

group, the 5-FU-treated group and the combined treatment group as compared to the control group. Tumor volumes in the salinomycin-treated group and the combined treatment group decreased significantly compared to the 5-FU-treated group (Fig. 6A). After 3 weeks of treatment, the animals were sacrificed and CRSC xenografts were dissected and weighed (Fig. 6B). The weight of tumors in the salinomycin-treated group and the combined treatment group were both significantly smaller than those in the 5-FU-treated and control groups $(\mathrm{P}<0.05)$.

\section{Discussion}

Recently salinomycin has been shown to induce apoptosis in several types of malignant cancer cells $(26,27)$. In the present study, we found that salinomycin inhibited the proliferation of CRSCs in vitro and reduced tumor growth in vivo. The pharmacologic action of salinomycin has attracted increased attention in recent years in view of its potential as a new cancer chemotherapeutic based on its activity as a selective inhibitor of breast cancer stem cells. Salinomycin treatment was also found to reduce the formation of metastatic nodules by CSCs $(19,28)$. Compared with drugs that kill general cancer cells, such as paclitaxel (3) and oxaliplatin (29), salinomycin selectively kills cancer stem cells, providing a new strategy for cancer therapy.

Our results demonstrated that salinomycin decreased the viability and proliferation of CRSCs in a time- and dose-dependent manner. The results also indicated that the
anti-CRSC properties of salinomycin are a result of apoptosis initiation. The results of the Annexin V-FITC and JC-1 staining assays provided evidence for early and late apoptosis, and necrosis in CRSCs treated with different concentrations of salinomycin. Research has shown that resistance to apoptosis is one of the main causes of tumorigenesis and tumor drug resistance (30), and the caspase and the Bcl-2 families play a significant role in the regulation of apoptosis. Caspase- 3 is a downstream molecule that is activated by upstream molecules such as caspase- 8 or -9 , leading to apoptosis. Pro-apoptotic Bax boosts essential apoptosis by forming oligomers in the mitochondrial outer membrane and promoting the release of apoptogenic molecules, while anti-apoptotic Bcl-2 blocks mitochondrial apoptosis by blocking the release and oligomerization of Bax (31). In the present study, molecular biology assays indicated that salinomycin dose-dependently activated cleaved caspase- $3,-8$ and -9 at both the mRNA and protein levels; salinomycin treatment also decreased the expression of the apoptotic protein $\mathrm{Bcl}-2$ and increased expression of the proapoptotic protein Bax. It was therefore demonstrated that salinomycin remedies the apoptosis resistance of CRSCs in vitro and in vivo, which may make it an effective chemotherapeutic agent for treating CRC.

In conclusion, we demonstrated that salinomycin suppressed the proliferation of CRSCs, vital for tumor development. In the present study, we demonstrated that salinomycin inhibited proliferation, induced apoptosis by increasing the activity of the caspase family (caspase-3, -8 and -9) and Bax, and by downregulating the activity of Bcl-2. Although the exact 
mechanism of the antitumor activity of salinomycin remains unclear, this research represents an important first step in the development of salinomycin-related colon cancer therapy.

\section{Acknowledgements}

The present study was supported by the Jilin Province Science Foundation (20120960).

\section{References}

1. Jemal A, Bray F, Center MM, Ferlay J, Ward E and Forman D: Global cancer statistics. CA Cancer J Clin 61: 69-90, 2011.

2. Jemal A, Center MM, Ward E and Thun MJ: Cancer occurrence. Methods Mol Biol 471: 3-29, 2009.

3. Nautiyal J, Kanwar SS, Yu Y and Majumdar AP: Combination of dasatinib and curcumin eliminates chemo-resistant colon cancer cells. J Mol Signal 6: 7, 2011.

4. Zhang N, Yin Y, Xu SJ and Chen WS: 5-Fluorouracil: Mechanisms of resistance and reversal strategies. Molecules 13 $1551-1569,2008$

5. Jiang WQ, Fu FF, Li YX, Wang WB, Wang HH, Jiang HP and Teng LS: Molecular biomarkers of colorectal cancer: Prognostic and predictive tools for clinical practice. J Zhejiang Univ Sci B 13: 663-675, 2012.

6. Simeone DM: Pancreatic cancer stem cells: Implications for the treatment of pancreatic cancer. Clin Cancer Res 14: 5646-5648, 2008.

7. Boman BM and Huang E: Human colon cancer stem cells: A new paradigm in gastrointestinal oncology. J Clin Oncol 26 2828-2838, 2008.

8. Vermeulen L, Sprick MR, Kemper K, Stassi G and Medema JP: Cancer stem cells - old concepts, new insights. Cell Death Differ 15: 947-958, 2008.

9. Shipitsin M and Polyak K: The cancer stem cell hypothesis: In search of definitions, markers, and relevance. Lab Invest 88: 459-463, 2008.

10. Fabrizi E, di Martino S, Pelacchi F and Ricci-Vitiani L: Therapeutic implications of colon cancer stem cells. World $\mathrm{J}$ Gastroenterol 16: 3871-3877, 2010.

11. Ong CW, Kim LG, Kong HH, Low LY, Iacopetta B, Soong R and Salto-Tellez M: CD133 expression predicts for non-response to chemotherapy in colorectal cancer. Mod Pathol 23: 450-457, 2010.

12. Saigusa S, Tanaka K, Toiyama Y, Yokoe T, Okugawa $\mathrm{Y}$, Kawamoto A, Yasuda H, Morimoto Y, Fujikawa H, Inoue Y, et al: Immunohistochemical features of CD133 expression: Association with resistance to chemoradiotherapy in rectal cancer. Oncol Rep 24: 345-350, 2010.

13. Sarkar B, Dosch J and Simeone DM: Cancer stem cells: A new theory regarding a timeless disease. Chem Rev 109: 3200-3208, 2009.

14. Mueller MT, Hermann PC, Witthauer J, Rubio-Viqueira B, Leicht SF, Huber S, Ellwart JW, Mustafa M, Bartenstein P, D'Haese JG, et al: Combined targeted treatment to eliminate tumorigenic cancer stem cells in human pancreatic cancer. Gastroenterology 137: 1102-1113, 2009.
15. Mahmoudi N, de Julián-Ortiz JV, Ciceron L, Gálvez J, Mazier D, Danis M, Derouin F and García-Domenech R: Identification of new antimalarial drugs by linear discriminant analysis and topological virtual screening. J Antimicrob Chemother 57: 489-497, 2006.

16. Mitani M, Yamanishi T, Miyazaki Y and Otake N: Salinomycin effects on mitochondrial ion translocation and respiration. Antimicrob Agents Chemother 9: 655-660, 1976.

17. Naujokat C, Fuchs D and Opelz G: Salinomycin in cancer: A new mission for an old agent. Mol Med Rep 3: 555-559, 2010.

18. Huczynski A: Salinomycin: A new cancer drug candidate. Chem Biol Drug Des 79: 235-238, 2012.

19. Gupta PB, Onder TT, Jiang G, Tao K, Kuperwasser C, Weinberg RA and Lander ES: Identification of selective inhibitors of cancer stem cells by high-throughput screening. Cell 138: 645-659, 2009.

20. Wang Y: Effects of salinomycin on cancer stem cell in human lung adenocarcinoma A549 cells. Med Chem 7: 106-111, 2011.

21. s22. Tang QL, Zhao ZQ, Li JC, Liang Y, Yin JQ, Zou CY, Xie XB, Zeng YX, Shen JN, Kang T, et al: Salinomycin inhibits osteosarcoma by targeting its tumor stem cells. Cancer Lett 311: 113-121, 2011.

23. Basu D, Montone KT, Wang LP, Gimotty PA, Hammond R, Diehl JA, Rustgi AK, Lee JT, Rasanen K, Weinstein GS, et al: Detecting and targeting mesenchymal-like subpopulations within squamous cell carcinomas. Cell Cycle 10: 2008-2016, 2011.

24. Ketola K, Hilvo M, Hyötyläinen T, Vuoristo A, Ruskeepää AL, Orešič M, Kallioniemi O and Iljin K: Salinomycin inhibits prostate cancer growth and migration via induction of oxidative stress. Br J Cancer 106: 99-106, 2012.

25. Zhang GN, Liang Y, Zhou LJ, Chen SP, Chen G, Zhang TP, Kang $\mathrm{T}$ and Zhao YP: Combination of salinomycin and gemcitabine eliminates pancreatic cancer cells. Cancer Lett 313: 137-144, 2011.

26. Kim KY, Yu SN, Lee SY, Chun SS, Choi YL, Park YM, Song CS Chatterjee B and Ahn SC: Salinomycin-induced apoptosis of human prostate cancer cells due to accumulated reactive oxygen species and mitochondrial membrane depolarization. Biochem Biophys Res Commun 413: 80-86, 2011.

27. Fuchs D, Heinold A, Opelz G, Daniel V and Naujokat C: Salinomycin induces apoptosis and overcomes apoptosis resistance in human cancer cells. Biochem Biophys Res Commun 390: 743-749, 2009.

28. Maitland NJ and Collins AT: Prostate cancer stem cells: A new target for therapy. J Clin Oncol 26: 2862-2870, 2008.

29. Dong TT, Zhou HM, Wang LL, Feng B, Lv B and Zheng MH: Salinomycin selectively targets ' $\mathrm{CD} 133^{+}$' cell subpopulations and decreases malignant traits in colorectal cancer lines. Ann Surg Oncol 18: 1797-1804, 2011.

30. Lee S and Schmitt CA: Chemotherapy response and resistance. Curr Opin Genet Dev 13: 90-96, 2003.

31. Leibowitz B and $\mathrm{Yu}$ J: Mitochondrial signaling in cell death via the Bcl-2 family. Cancer Biol Ther 9: 417-422, 2010. 